\title{
Financial Management for UMKM at the RW Level Discussion Forum in Tangerang City
}

\author{
Afaf Boru Bulan Namora ${ }^{1 *}$, Djenni Sasmita ${ }^{1}$ \\ ${ }^{1}$ Universitas Muhammadiyah Tangerang \\ *Email: jennysasmita0@gmail.com
}

\begin{abstract}
The main objective of community service is to carry out financial management for MSMEs at RW level in Tangerang City. Micro, Small, and Medium Enterprises (MSMEs) are micro, small and medium enterprises which are one of the business sectors that still survived during the Indonesian economic crisis in 1998. These businesses can survive, because they do not depend on import trade or expect funding from banks. This financial management is carried out in a discussion forum at the RW level in the city of Tangerang to improve the welfare of the community in managing finances for micro businesses independently. The government realizes that financial management is one of the places for the community to empower and develop MSMEs. This service activity is carried out to manage finances in detail and properly managed at the RW level, Tangerang city. This implementation method consists of seminars and training. The results of the seminar and financial management training at the RW level discussion forum in the city of Tangerang went well because the participants received knowledge that was useful for training for the progress of their business. Based on the results of research carried out conducting umkm activities can improve detailed and correct financial management even though many people do not understand financial reporting in accounting, but because of the holding of seminars and training it has produced good results for the people of Tangerang city, thereby reducing unemployment.
\end{abstract}

\section{Keyword: Financial management, MSMEs, discussion forums}

\begin{abstract}
Abstrak
Tujuan utama pengabdian masyarakat adalah melakukan pengolalaan keuangan bagi UMKM tingkat RW di Kota Tangerang. Usaha Mikro, Kecil, dan Menengah (UMKM) adalah usaha mikro kecil dan menegah merupakan salah satu sektor usaha yang masih bertahan saat krisis ekonomi Indonesia pada tahun 1998. Usaha ini bisa bertahan, karena tidak bergantung pada perdagangan impor atau mengharapkan pendanaan dari perbankan. Pengolaan keuangan ini dilakukan di forum diskusi tingkat RW di kota Tangerang untuk meningkatkan kesejahteraan masyarakat dalam mengelola keuagan bagi usaha mikro secara mandiri. Pemerintah menyadari pengolaan keuangan merupakan salah satu wadah untuk masyarakat memberdayaka dan mengembangkan UMKM. Kegiatan pengabdian ini dilakukan untuk mengelola keuangan secara terperinci dan secara benar dikelola dengan baik ditingkat RW sekota Tangerang. Metode pelaksanaan ini merupakan seminar dan pelatihan. Hasil dari kegiatan seminar dan pelatihan pengelolaan keuangann di forum diskusi tingkat RW di kota Tangerang berjalan dengan lancar karena peserta mendapatkan ilmu yang bermanfaat pelatihan bagi kemajuan usaha mereka. Bedasarkan hasil penelitian yang dilakukan melakukan kegiatan umkm dapat meningkatkan penglolaan keuangan yang secara terperinci dan secara benar meskipun banyak masyarakat yang belum memahami laporan keuangan secara akuntansi, namun karena diadakannya seminar dan pelatihan membuahkan hasil yang baik untuk masyarakat sekota Tangerang, sehingga mengurangi angka pengangguran.
\end{abstract}

Kata Kunci: Pengelolaan keuangan, UMKM, forum diskusi

\section{PENDAHULUAN}

Peran Usaha Mikro Kecil dan Menengah (UMKM) dalam pertumbuhan perekonomian suatu negara dinilai penting. UMKM memiliki kontribusi besar dan krusial bagi perekonomian Indonesia. Usaha Mikro Kecil dan Menengah (UMKM) memegang peranan (Kompas, 2019). Program pengembangan Usaha Mikro, Kecil, dan Menengah (UMKM) sebagai salah satu instrument untuk menaikkan daya beli masyarakat, pada akhirnya akan menjadi katup pengaman dari situasi krisis moneter. 
Pengembangan UMKM menjadi sangat strategis dalam menggerakkan perekonomian nasional, mengingat kegiatan usahanya mencakup hampir semua lapangan usaha sehingga kontribusi UMKM menjadi sangat besar bagi peningkatan pendapatan (Naditya et al., 2013). Namun, di tengah peningkatan tersebut, kesulitan pemasaran, keterbatasan modal finansial, keterbatasan Sumber Daya Manusia (SDM), permasalahan bahan baku dan keterbatasan teknologi menjadi kendala pengembangan UMKM yang selalu disebut di berbagai forum diskusi dan penelitian. Sesungguhnya, terdapat masalah mendasar yang harus segera dituntaskan dan menjadi prioritas langkah dalam pemberdayaan dan pendampingan UMKM. Pengelolaan keuangan menjadi salah satu aspek penting bagi kemajuan perusahaan. Pengelolaan keuangan harus dilakukan secara benar. Melakukan pengelolaan keuangan yang baik melalui akuntansi.

Akuntansi adalah seperangkat pengetahuan yang mempelajari perekayasaan penyediaan jasa berupa informasi keuangan kuantitatif unit-unit organisasi dalam suatu lingkungan negara tertentu dan cara penyampaian (pelaporan) informasi tersebut kepada pihak yang berkepentingan untuk dijadikan dasar dalam pengambilan keputusan ekonomik (Elias \& Shaver, 1997).

Pengembangan Usaha Mikro Kecil dan Menengah, pada hakekatnya merupakan tanggung jawab bersama antara pemerintah dan masyarakat. Dengan mencermati permasalahan yang dihadapi oleh Pelaku Usaha Mikro Kecil dan Menengah, maka kedepan perlu diupayakan hal-hal sebagai berikut:

a. Penciptaan iklim usaha yang kondusif

Perlu mengupayakan terciptanya iklim yang kondusif antara lain dengan mengusahakan ketentraman dan keamanan berusaha serta penyederhanaan prosedur perijinan usaha keringanan pajak dan sebagainya.

b. Bantuan Permodalan

Perlu memperluas skim kredit khusus dengan syarat-syarat yang tidak memberatkan bagi Usaha Mikro Kecil dan Menengah, untuk membantu peningkatan permodalannya, baik itu melalui sektor jasa, financial formal, sektor jasa financial informasi skema penjaminan, leasing dan dana modal ventura.

c. Perlindungan Usaha

Perlindungan usaha jenis-jenis usaha tertentu, terutama jenis usaha tradisional yang merupakan usaha golongan ekonomi lemah, harus mendapatkan perlindungan dari pemerintah, baik itu melalui undang-undang maupun peraturan pemerintah yang bermuara kepada saling menguntungkan.

d. Pengembangan Kemitraan

Pengembangan kemitraan perlu dikembangkan, kemitraan yang saling membantu antara UMKM, atau antara UMKM dengan pengusaha besar di dalam negeri maupun luar negeri, untuk menghindarkan terjadinya monopoli dalam usaha. Di samping itu juga untuk memperluas pangsa pasar dan pengelolaan bisnis yang lebih efisien. Dengan demikian UMKM akan mempunyai kekuatan dalam bersaing dengan pelaku bisnis lainnya, baik dari dalam maupun luar negeri.

e. Pelatihan Pemerintah

Pelatihan pemerintah perlu meningkatkan pelatihan bagi UMKM baik dalam aspek kewiraswastaan, manajemen, administrasi dan pengetahuan serta keterampilannya dalam pengembangan usaha. Di samping itu juga perlu diberi kesempatan untuk menerapkan hasil pelatihan di lapangan untuk mempraktekkan teori melalui pengembangan kemitraan rintisan.

f. Membentuk Lembaga Khusus

Membentuk lembaga khusus perlu dibangun suatu lembaga yang khusus bertanggung jawab dalam mengkoordinasikan semua kegiatan yang berkaitan dengan upaya penumbuh kembangan UMKM dan juga berfungsi untuk mencari solusi dalam rangka mengatasi permasalahan baik internal maupun eksternal yang dihadapi oleh UMKM.

Usaha ini bisa bertahan karena tidak bergantung pada perdagangan impor atau mengharahpkan pendanaan dari perbankan. penyebab sulitnya UMKM memperoleh akses 
pembiayaan perbankan adalah berisi urgensi dan latar belakang masalah pengabdian kepada masyarakat yang diuraikan dengan metode piramida terbalik mulai dari tingkat global, nasional dan lokal. (Kompas, 2015)

\section{METODE PELAKSANAAN}

Pelaksanaan kegiatan pengabdian pada masyarakat ini dilakukan dengan menggunakan metode ceramah, tutorial, dan diskusi. Adapun tahapan pelaksanaan kegiatan pengabdian ini sebagai berikut:

a. Metode Ceramah

Metode ceramah adalah cara penyajian pelajaran yang dilakukan oleh guru dengan penuturan atau penjelasan secara langsung dihadapan peserta didik. (Martono, 2010)(Martono, 2010). Langkah pertama ini dengan memberikan wawasan kepada peserta mengenai pentingnya pengelolaan keuangan.

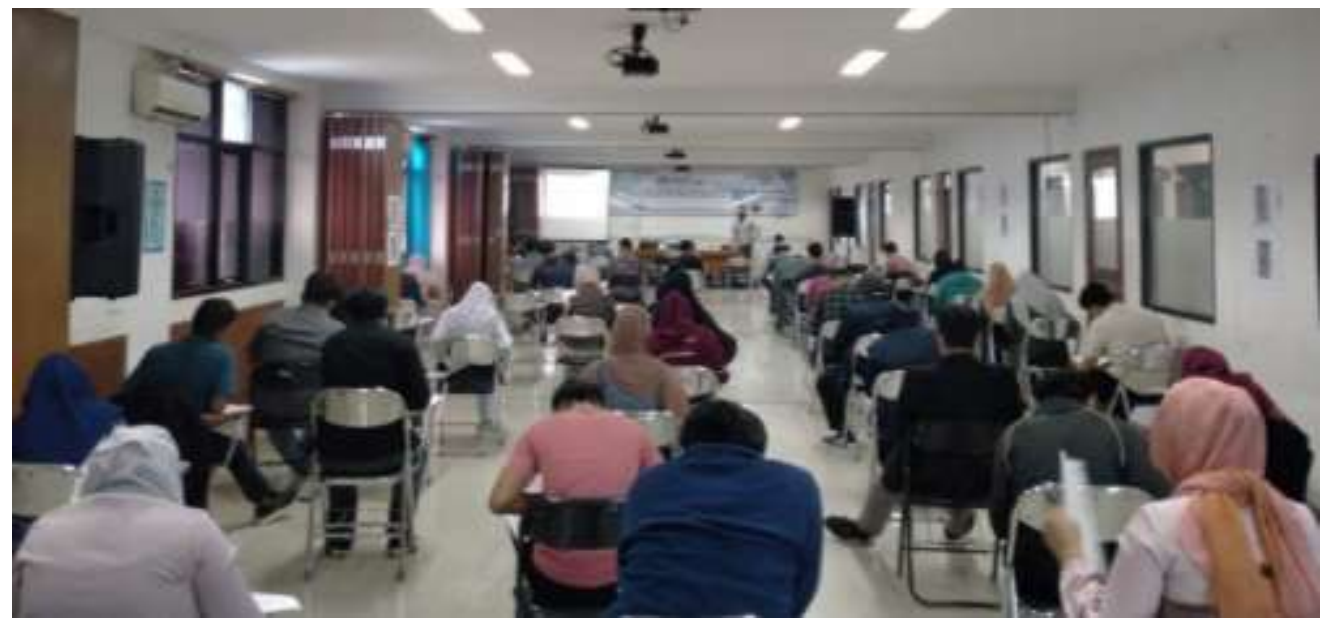

Gambar 2.1. Pemberian ceramah

b. Metode Tutorial

Menurut kamus besar bahasa indonesia (KBBI), tutorial adalah pembimbingan kelas oleh seorang pengajar (tutor) untuk seorang peserta didik (Kemdikbud, 2016). Langkah kedua, para peserta pelatihan diberikan materi tentang penyusunan laporan keuangan, meliputi laporan laba/rugi, laporan perubahan modal, neraca, serta laporan arus kas. Materi ini disampaikan dalam bentuk tutorial disertai latihan/studi kasus.

c. Metode Diskusi

Diskusi adalah suatu proses penglibatan dua atau lebih individu yang berinter aksi secara verbal dan saling berhadapan muka mengenai tujuan atau sasaran yang sudah tertentu melauli cara tukar menukar informasi (information sharing), mempertahankan diri (self-maintenance) atau pemecahan masalah (problem-solving) (Anonim, 2020). Langkah ketiga, para peserta pelatihan diberikan kesempatan untuk mendiskusikan permasalahan yang berkaitan dengan usaha yang mereka miliki.

\section{HASIL DAN PEMBAHASAN}

Pelaksanaan pelatihan dibagi dalam 3 tahap selama 2 hari.

a. Pada hari pertama diawali dengan regisrasi dan pembukaan.

b. Dilanjutkan dengan pemberian materi pertama dengan topik materi Pengantar Pengelolaan Keuangan dan Modal Kerja bagi UKM. 
Materi ini membahas pentingnya perencanaan dan pengelolaan keuangan bagi UKM. Materi pertama kedua ini juga disampaikan dengan topik transaksitransaksi modal kerja dan pelaporan modal kerja UKM, yaitu:

a. Pelatihan hari kedua materi disampaikan oleh pemateri dengan topik praktik pengelolaan keuangan UKM.

b. Kemudian, pada hari terakhir pelatihan ini peserta diminta mencatat transaksi bisnis keuangan dan modal kerja berdasarkan bisnis masing-masing dan selanjutnya menyusun pelaporan modal kerja.

c. Pada sesi terakhir ini kegiatan pelatihan diakhiri pada jam 15.00.

d. Selanjutnya sisa pelatihan 7,5 jam digunakan untuk pendampingan kepada peserta pelatihan pengelolaan keuangan UMKM secara mandiri di masing-masing tempat.

Pelaksanaan pelatihan pada hari pertama berjalan dengan lancar. Materi pertama yang diberikan adalah pengenalan atau pendahuluan mengenai keuangan UMKM. Pemateri memberikan penjelasan pentingnya perencanaan keuangan dan pengelolaannya serta modal kerja yang likuid bagi UMKM. Sebagian besar audiens belum mengerti fungsi keuangan dan modal kerja, bahkan sebagian besar peserta pelatihan menganggap bahwa perencanaan keuangan dan pengelolaannya adalah bidang yang rumit, susah, merepotkan, menghabiskan waktu.

a. Materi pertama ini diisi dengan penguatan pentingnya perencanaan dan pengelolaan keuangan bagi usaha kecil (UMKM). Pada sesi ini terjadi diskusi yang menarik antara audiens dengan pemateri mengenai konsep dasar keuangan untuk usaha. Beberapa audiens memiliki persepsi berbeda tentang usaha atau entitas. Berdasarkan diskusi konsep entitas ini akhirnya diperoleh pemahaman konsep entitas.

b. Setelah diperoleh kesepakatan tentang konsep entitas, dilanjutkan dengan fungsi perencanaan dan pengelolaan serta pelaporan keuangan bagi entitas.

c. Setelah acara ISHOMA selama satu jam acara dilanjutkan dengan materi kedua mengenai transaksi-transaksi dalam modal kerja untuk likuiditas usaha.

d. Pada sesi kedua, masing-masing audiens diminta menjelaskan aktivitas operasi usaha mereka. Selanjutnya diidentifikasi aktivitas-aktivitas ekonomi dan aktivitas nonekonomi. Berdasarkan aktivitas ekonomi yang telah diidentifikasi

e. Selanjutnya dilakukan pencatatan akuntansi dan modal kerja yang penting bagi kontinuitas usaha. Aktivitas yang diidentifikasi tersebut diawali dari aktivitas memulai usaha (investasi awal), transaksi pembelian bahan baku, pembelanjaan, pemasukan, dll. Setelah mencatat transaksi modal kerja dan pengelolaannya,

f. Materi berikutnya menyusun laporan perencanaan dan modal kerja. Sebagai latihan, peserta pelatihan diminta membuat laporan keuangan sederhana berdasarkan contoh yang ada. Latihan ini berakhir pada pukul 15.00 sore.

g. Sebelum peserta pelatihan pulang, pemateri memberikan tugas berupa identifikasi transaksi yang terjadi di masing-masing usaha mereka.

Pelatihan hari kedua materi praktik akuntansi UMKM yang dilanjutkan kembali dari materi sebelumnya. Pada akhir pelatihan, peserta diminta mengumpulkan mencatat transaksi bisnis berdasarkan bisnis masingmasing yang telah disiapkan dari rumah. Pada sesi awal ini peserta bertanya dan berdiskusi tentang transaksi dan pencatatan yang telah mereka buat.

Beberapa dari peserta masih kebingungan mencatat dan membuat perencaan serta pengelolaannya. Sesi pertama ini cukup menyita waktu, karena pembahasan transaksi dan pencatatan akuntansi dilakukan satu satu. Setelah semua peserta menyelesaikan pembuatan perencanaan dan pelaporan keuangan, peserta beristirahat untuk mekan siang dan melakukan ibadah. Setelah beristirahat diskusi dilanjutkan membahas penyusunan perencanaan dan pelaporan keuangan. Pada sesi terakhir ini peserta diminta menyusun perencanaan keuangan dan bagaimana melakukan pengelolaan keuangan berdasarkan transaksi dan rencana yang telah mereka buat. Pada sesi terakhir ini kegiatan pelatihan diakhiri pada jam 15.00 . 
Selanjutnya sisa pelatihan 7,5 jam digunakan untuk pendampingan kepada pesrta pelatihan perencaaan dan pengelolaan keuangan UMKM secara mandiri di masing-masing tempat. Faktor Pendukung Kegiatan Secara umum acara pelatihan ini berjalan dengan lancar. Hal ini dicapai berkat dukungan Pemerintah kota Tangerang yaitu fasilitas tempat serta bantuan dalam mengumpulkan audiens peserta. PemKab kota Tangerang menyambut baik acara pelatihan ini sehingga berkeinginan agar pelatihan ini tetap berlanjut di masa yang akan datang untuk kemajuan anggotanya. Faktor Penghambat Kegiatan Acara PPM dapat terlaksana dengan lancar karena pembagian tugas telah dilakukan jauh hari sebelum acara ini dilaksanakan. Hambatan lain yang dijumpai tim PPM adalah keikutsertaan atau kehadiran peserta yang tidak seratus persen hadir, yaitu hanya 47 peserta yang hadir dari 54 undangan. Hal ini diduga karena beberapa peserta yang diundang memiliki kegiatan di tempat lain, seperti mengikuti pameran di luar kota, pelatihan yang diselenggarakan instansi lain.

\section{KESIMPULAN}

Kegiatan pelatihan perencanaan dan pengelolaan keuangan serta modal kerja bagi usaha mikro, kecil, menengah (UMKM) untuk meningktakan kinerja keuangan perusahaan berjalan dengan lancar. Semua peserta antusias mengikuti acara hingga selesai dan merasakan manfaat pelatihan bagi kemajuan usaha mereka. Pelatihan serupa dapat dilaksanakan kembali dengan peserta (audience) yang lebih banyak/luas, dan dengan topik lainnya. Di samping itu fasilitas untuk presentasi seperti LCD dan pengeras suara sebaiknya diperiksa kembali sebelum acara dilaksanakan.

\section{UCAPAN TERIMAKASIH}

Tim pengabdian menyampaikan terimakasih kepada Rektor Universitas Sumatera Utara melalui lembaga pengabdian masyarakat atas program mono tahun dana NON PNBP Universitas Sumatera Utara nomor 287/UN5.2.3.2.1/PPM/2020. Tim juga menyampaikan terimakasih kepada mitra pada kegiatan pengabdian ini.

\section{DAFTAR PUSTAKA}

Elias, R., \& Shaver, J. (1997). Paul Grady and his contributions to accounting and auditing. The Accounting Historians Notebook, 20(2), 5.

Kemdikbud. (2016). Kamus Besar Bahasa Indonesia. Badan Pengembangan Dan Pembinaan Bahasa. kbbi.kemdikbud.go.id/entri/metodetutorial

Kompas. (2015). Problematika Apa saja yang Dihadapi UMKM di Indonesia? Kompas.Com. https://www.kompasiana.com/ussisa/565e27124623bdb70eba545b/problematika-apa-saja-yangdihadapi-umkm-di-indonesia?page=all

Kompas. (2019). Peran UMKM dalam Perekonomian Indonesia. Kompas.Com. https://www.kompas.com/skola/read/2019/12/20/120000469/peran-umkm-dalam-perekonomianindonesia?page=all\#: :text=Dilansir dari situs Bappenas\%2C di,untuk menjalankan kegiatan ekonomi produktif.)

Martono, N. (2010). Metode Penelitian Kualitatif. Rajagrafindo Persada.

Naditya, R., Suryono, A., \& Rozikin, M. (2013). Pengembangan Usaha Mikro, Kecil, Dan Menengah (Umkm) Melalui Fasilitasi Pihak Eksternal Dan Potensi Internal. Universitas Brawijaya, Malang, 1(6), 1086-1095. 